\title{
Variations in Sugar and Organic Acid Content of Fruit Harvested from Different Vaccinium uliginosum Populations in the Changbai Mountains of China
}

\author{
Yu Wang, Haobo Yang, Shuai Zhong, Xin Liu, Tong Li, and Chengwen Zong \\ Agriculture College of YanBian University, Yanji, Jilin 133002, People's Republic of China
}

\begin{abstract}
AdDitional INDEX words. altitude, bog bilberry, germplasm resource, high-performance liquid chromatography, latitude
ABstract. Sugar and organic acid contents as well as sugar-to-acid ratio of fruit are important factors affecting fruit quality and processing. In this study, we compared sugar and organic acid contents of Vaccinium uliginosum (bog bilberry) fruit harvested from 100 plants across 10 wild populations growing in the Changbai Mountains of China. Correlation of sugar and acid contents with the spatial distribution of these populations was accessed. Germplasm with high sugar and low acid with potential for use in future breeding was also identified. Results showed that sugar and organic acid contents varied among different $V$. uliginosum populations in the Changbai Mountains. Fructose $\left(18.60-38.54 \mathrm{mg} \cdot \mathrm{g}^{-1}\right)$ and glucose $\left(15.77-35.08 \mathrm{mg} \cdot \mathrm{g}^{-1}\right)$ were the main sugars, whereas quinic $\left(16.06-20.97 \mathrm{mg} \cdot \mathrm{g}^{-1}\right)$, citric (10.39-14.96 $\left.\mathrm{mg} \cdot \mathrm{g}^{-1}\right)$, and malic $\left(4.28-7.47 \mathrm{mg} \cdot \mathrm{g}^{-1}\right)$ acids were the main organic acids in $V$. uliginosum. The first population collected in the Dongfanghong forest farm (lat. $42^{\circ} 00^{\prime} \mathrm{N}$, long. $128^{\circ} 03^{\prime} \mathrm{E}$ ) showed the highest average sugar content and sugar-to-acid ratio among the sampled populations. Moreover, total sugar content and sugar-to-acid ratio of Sample 7-Population 1, which is located at Manjiang forest farm (lat. $41^{\circ} 09^{\prime} \mathrm{N}$, long. $127^{\circ} 05^{\prime} \mathrm{E}$ ) was much higher than the other 99 samples, making this sample representative of important germplasm for breeding. Altitude and latitude were important environmental factors affecting sugar and organic acid contents. Fructose, glucose, and total sugar contents were positively correlated with altitude and negatively correlated with latitude. Oxalic acid content and sugar-to-acid ratio were positively correlated with altitude, and there was no significant correlation between organic acid contents and latitude.
\end{abstract}

Vaccinium uliginosum (bog bilberry) is a perennial deciduous shrub, and it is the most widely distributed species of Vaccinium in the world (Kim et al., 2009). In North America, it is mainly distributed across the Arctic in Alaska and Canada but is also found southward in the Rocky Mountains and Sierra Nevada and in the northeastern United States. In Europe, V. uliginosum is found in parts of Scandinavia as well as the Pyrenees and Alps; the Caucasus Mountains in Eurasia; and China, Mongolia, central Japan, South Korea, and North Korea in Asia. In China, $V$. uliginosum is mainly distributed in the Daxing'an, Xiaoxing'an, and Changbai Mountains (Jacquemart, 1996; Su et al., 2016; Wu et al., 2005; Yang et al., 2018). The Changbai Mountains harbor extensive wilderness areas of intact ecosystems with native vegetation, including $V$. uliginosum, which is distributed throughout the mountains at various altitudes and latitudes. The annual wild harvest of $V$. uliginosum in China is 7 million kilograms, which is primarily used for producing wine, juice, jam, and preserved products (Zong et al., 2011).

Anthocyanins, flavonoids, phenols, and organic acids in $V$. uliginosum fruit show various biological properties, including anticancer and antioxidative effects, and they are also beneficial for eyesight (Kraujalyte et al., 2015; Liu et al., 2010; Yin et al., 2012).

Received for publication 15 May 2019. Accepted for publication 7 Sept. 2019. We thank the staff of Lanjia forest farm for their help in the collection of experimental materials. This work was funded by the China National Science Foundation (grant nos. 31760557 and 31460504).

C.Z. is the corresponding author. E-mail: zongchengwen@aliyun.com.
A fruit's sugar and organic acid contents affect its quality and flavor (Makus and Morris, 1987; Ryan and Dupont, 1973; Saftner et al., 2008). Specifically, total sugar content has a great influence on fruit quality, and it is one of the criteria determining alcohol content. Organic acids can improve wine color, although high organic acid contents detrimentally affect wine flavor (Liu et al., 2006; Poll, 1981). Fructose, glucose, and sucrose are the main soluble sugars (Hirvi and Honkanen, 1983), whereas quinic acid, followed by citric and malic acids, are the main organic acids in $V$. uliginosum fruit (Wei et al., 2014). Vitamin $C$ is a well-known antioxidant (Kalt et al., 1999). Fediuk et al. (2002) reported that $V$. uliginosum fruit contain abundant vitamin C. During ripening, acid content changes due to the accumulation of sugars (Barett et al., 2005). Moreover, sugar-to-acid ratio influences fruit flavor and is an indicator of optimal harvest time (Kafkas et al., 2006). Low sugar and high acid content make the fruit taste more acidic. In contrast, high sugar and low acid content enhance fruit taste, whereas very low sugar and acid content make the fruit bland (Wang et al., 2009).

Genetic differences can affect fruit metabolism (Lätti et al., 2008; Mikulic et al., 2015). There are differences in ploidy levels of $V$. uliginosum populations in the Changbai Mountains. For example, $V$. uliginosum is tetraploid at an altitude of $\approx 900 \mathrm{~m}$ and diploid at an altitude of $>1700 \mathrm{~m}$. Moreover, $V$. uliginosum ssp. alpinum and $V$. uliginosum var. leucocarpum are distributed in parts of the Changbai Mountains ( $\mathrm{Su}$ et al., 2016). In addition to variations in genetic factors associated with metabolic components and contents of fruit (Zheng et al., 2011), environmental factors, such as soil type, temperature, 
and light regimes, and spatial distribution strongly affect growth and metabolites of $V$. uliginosum (Graae et al., 2008). Lätti et al. (2010) found that anthocyanin and flavonol glycoside contents of $V$. uliginosum fruit increased with latitude, and Wang et al. (2014) found that flavonoid contents increased with altitude in the Xiaoxing'an Mountains. Many studies have focused on the content of anthocyanin and flavonoids in $V$. uliginosum. However, there is no report on the sugar, organic acid composition, and content of $V$. uliginosum fruit in the Changbai Mountains and their association with the spatial distribution of plant populations.

In this study, we examined sugar and organic acid compositions and contents of $V$. uliginosum fruit using high-performance liquid chromatography. We assessed the correlation of sugar and organic acid contents of $V$. uliginosum fruit with the spatial distribution of populations they were harvested from. Finally, The germplasm resources of $V$. uliginosum in the Changbai Mountains were evaluated to provide scientific basis for $V$. uliginosum breeding.

\section{Materials and Methods}

Plant material and growing conditions. This test collected plant fruit samples from 10 different wild $V$. uliginosum populations inhabiting the Changbai Mountains of China (lat. $38^{\circ} 46^{\prime} \mathrm{N}$ to $47^{\circ} 00^{\prime} \mathrm{N}$, long. $121^{\circ} 08^{\prime} \mathrm{E}$ to $134^{\circ} 00^{\prime} \mathrm{E}$ ): the Manjiang forest farm (MJ), the Dongfanghong forest farm (DFH), and the Lanjia forest farm (LJ). At each location, fruit samples were collected from 10 randomly selected bushes with the restriction that the distance between samples was at least $30 \mathrm{~m}$, to ensure that they originated from different genets. The growth types are shown in Table 1 . We collected 10-fruit samples per population, for a total of 100 samples. Each sample consisted of 20-30 mature fruit (60 d after full bloom). After collecting fruit from a given site, the least damaged mature fruit were selected and stored at $-20^{\circ} \mathrm{C}$ until sugar and organic acid analyses could be performed.

Chemicals. The following chemicals were used in our study: oxalic acid, citric acid, shikimic acid, vitamin C (ascorbic acid), L-malic acid, D-quinic acid, fructose, glucose, sucrose [chromatographically pure (Beijing TanMo Quality Inspection Technology Co., Beijing, China)], methanol, acetonitrile [chromatographically pure (Tianjin Furui Chemical Reagent Co., Tianjin, China)], phosphoric acid and potassium dihydrogen phosphate [chromatographically pure (Shanghai Aladdin Biochemical Technology Co., Shanghai China)], and laboratory ultra-pure water.

SAMPle AND STANDARD PREPARATION. To extract organic acids, we precision-weighed $5.0 \mathrm{~g}$ of $V$. uliginosum fruit from each sample and added $5 \mathrm{~mL}$ of mobile phase $(0.01$ $\left.\mathrm{mol} \cdot \mathrm{L}^{-1} \mathrm{~K}_{2} \mathrm{HPO}_{4}, \mathrm{pH} 2.5\right)$ before grinding the sample into a homogenate. We then sonicated the sample for $5 \mathrm{~min}$, centrifuged it at $9982 g_{\mathrm{n}}$. for $15 \mathrm{~min}$, and then collected the supernatant. The centrifuged filter residue was extracted once as described above, and then the mobile phase was adjusted to a volume of $25 \mathrm{~mL}$. We used a $0.45-\mu \mathrm{m}$ aqueous filter to extract organic acids.

To extract sugars for analysis, we precision-weighed $1.0 \mathrm{~g}$ of $V$. uliginosum fruit and added $5 \mathrm{~mL}$ of ultrapure water before grinding the sample into a homogenate. This was then sonicated for $5 \mathrm{~min}$, centrifuged it at $9982 g_{\mathrm{n}}$ for $15 \mathrm{~min}$, and then collected the supernatant. (The filter residue was extracted again in the above manner.) Then the volume of the mobile phase was adjusted to $20 \mathrm{~mL}$ with ultrapure water and filtered through a $0.45-\mu \mathrm{m}$ filter to extract sugars.

To prepare standards, we combined $50 \mathrm{mg}$ each of oxalic acid, malic acid, citric acid, shikimic acid, vitamin $\mathrm{C}$, and quinic acid to prepare a $10-\mathrm{mL}$ solution with mobile phase. Then filtered the solution through a $0.45-\mu \mathrm{m}$ filter to obtain organic acids mixed with a concentration of $5 \mathrm{mg} \cdot \mathrm{mL}^{-1}$ stock solution. We added $100 \mathrm{mg}$ each of fructose, glucose, and sucrose to $10 \mathrm{~mL}$ of ultrapure water and filtered the solution through a $0.45-\mu \mathrm{m}$ filter to obtain a sugar mixture of stock solution at a concentration of $10 \mathrm{mg} \cdot \mathrm{mL}^{-1}$.

Chromatographic conditions. We used an ultraviolet detection high-performance liquid chromatography (Primaide, Hitachi Production Co., Tokyo, Japan) to estimate organic acid$\mathrm{s}$ and a $4.6 \times 250-\mathrm{mm}, 5-\mu \mathrm{m}$ chromatograph column (Zorbax SB-Aq; Agilent Technologies, Santa Clara, CA). The mobile phase consisted of $0.01 \mathrm{~mol} \cdot \mathrm{L}^{-1} \mathrm{~K}_{2} \mathrm{HPO}_{4}(\mathrm{pH} 2.5)$ with a flow rate of $0.5 \mathrm{~mL} \cdot \mathrm{min}^{-1}$. We set the column temperature at $30{ }^{\circ} \mathrm{C}$ and ultraviolet detection wavelength at $210 \mathrm{~nm}$ (at $245 \mathrm{~nm}$ for detecting vitamin C). Sample size was $10 \mu \mathrm{L}$.

For evaluating sugars, we used an evaporative light scattering detector [ELSD (3300; Alltech, Chicago, IL)], $4.6 \times 250$ $\mathrm{mm}, 5-\mu \mathrm{m}$ chromatography column (CAPCELL PAK $\mathrm{NH}_{2}$ UG80 S5; Shiseido Co., Tokyo, Japan). The mobile phase consisted of acetonitrile and water mixture $(75: 25 \mathrm{v} / \mathrm{v})$. The

Table 1. Sampling information of plant fruit samples from 10 wild Vaccinium uliginosum populations from the Changbai Mountains of China. At each location, fruit samples were collected from 10 randomly selected bushes with the restriction that the distance between samples was at least $30 \mathrm{~m}$ to ensure that they originated from different genets. We collected 10-fruit samples per population, for a total of 100 samples. Each sample consisted of 20 to 30 mature fruit ( $60 \mathrm{~d}$ after full bloom).

\begin{tabular}{|c|c|c|c|c|}
\hline Population $^{z}$ & Plot location & Altitude (m) & Site type & Soil type \\
\hline$\overline{\mathrm{MJ}}$ & $41^{\circ} 09^{\prime} \mathrm{N} 127^{\circ} 05^{\prime} \mathrm{E}$ & 885 & Mountainous & Sandy loam \\
\hline DFHII & $42^{\circ} 01^{\prime} \mathrm{N} 128^{\circ} 03^{\prime} \mathrm{E}$ & 1225 & Humic & Loam \\
\hline LJII & $43^{\circ} 04^{\prime} \mathrm{N} 130^{\circ} 08^{\prime} \mathrm{E}$ & 830 & Bryophytic & Clay \\
\hline LJIII & $43^{\circ} 04^{\prime} \mathrm{N} 130^{\circ} 07^{\prime} \mathrm{E}$ & 835 & Bryophytic & Clay \\
\hline LJIV & $43^{\circ} 04^{\prime} \mathrm{N} 130^{\circ} 08^{\prime} \mathrm{E}$ & 838 & Humic & Loam \\
\hline LJVII & $43^{\circ} 04^{\prime} \mathrm{N} 131^{\circ} 00^{\prime} \mathrm{E}$ & 740 & Meadow & Loam \\
\hline
\end{tabular}

${ }_{\mathrm{z}}^{\mathrm{MJ}}=$ Manjiang forest farm; DFH $=$ Dongfanghong forest farm; LJ = Lanjia forest farm. 
ELSD with a flow rate of $1 \mathrm{~mL} \cdot \mathrm{min}^{-1}$; column temperature was $35^{\circ} \mathrm{C}$ and drift tube temperature was $80^{\circ} \mathrm{C}$. Sample size was 5 $\mu \mathrm{L} . \mathrm{N}_{2}$ was used as a carrier gas, with an $\mathrm{N}_{2}$ flow rate of 1 $\mathrm{L} \cdot \mathrm{min}^{-1}$ and a gain value of 1.0 .

RELATED CALCULATIONS. We calculated the concentration of each component by comparing the peak area of the sample with its corresponding regression equation, expressed in milligrams per gram.

Total acid content $=$ oxalic acid content + citric acid content + shikimic acid content + vitamin $C$ content + malic acid content + quinic acid content total sugar content = fructose content + glucose content $;$ sugar-to-acid ratio = total sugar content/total acid content.

Statistical analyses. All experiments were performed in triplicates. This test used spreadsheet software (Excel 2010; Microsoft Corp., Redmond, WA) to process raw data and calculate means and standard errors. Analysis of variance was performed with SPSS (version 19.0; IBM Corp., Armonk, NY).
No homogeneity of variance was analyzed by Kruskal-Wallis test of nonparametric statistics with SPSS (version 19.0). We used the Mann-Whitney test in nonparametric statistics to individually analyze the data of $V$. uliginosum from different populations. We considered probability values of $\leq 0.05$ to be statistically significant. We verified any linear relationship between parameters with SPSS and determined the degree of correlation with Pearson correlation coefficients. We ran principal component analysis (PCA), fitting the analysis and violin chart using OriginPro (version 2018; OriginLab, Northampton, MA) (Wu et al., 2003).

\section{Results and Discussion}

Compositional profile. The peak value is determined based on retention time. Chromatograms of standard solutions of sugars, organic acids, and vitamin $\mathrm{C}$ are shown in Fig. 1. All standards for sugars and organic acids reached the baseline separations with distinctive peaks. Chromatogram of a $V$. uliginosum sample solution is shown in Fig. 2. Sucrose was not detected.
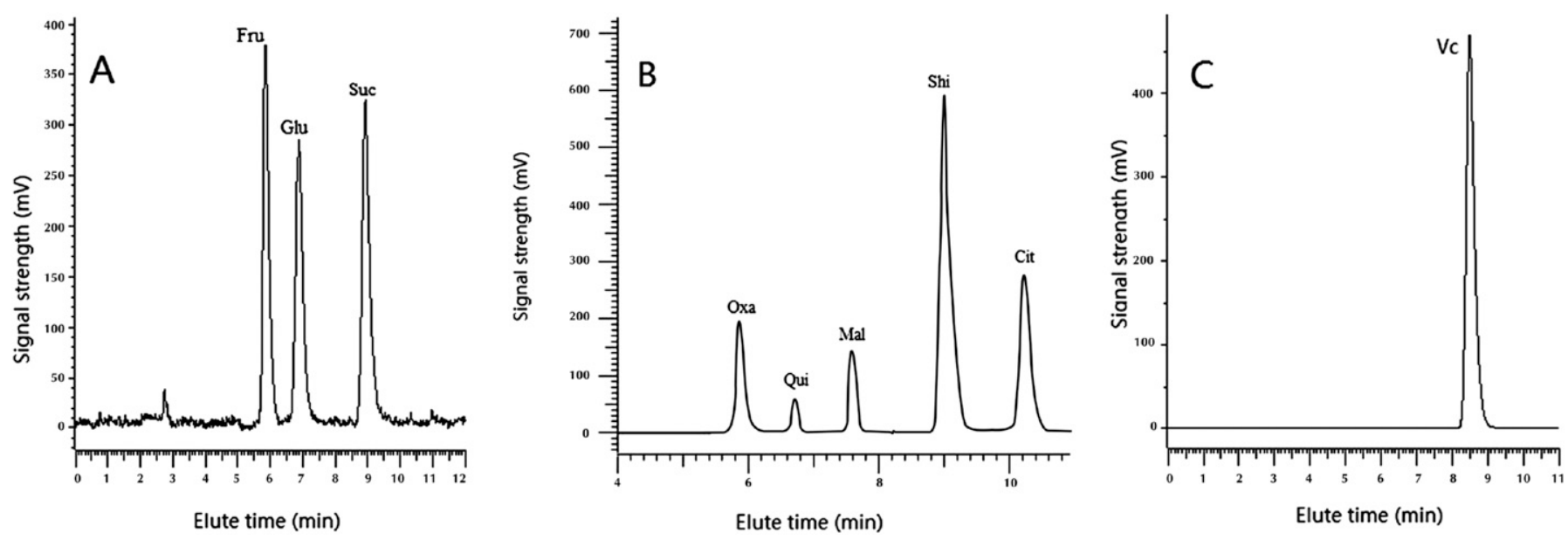

Fig. 1. High-performance liquid chromatogram of sugar and organic acids in Vaccinium uliginosum standard under optimized conditions: $(\mathbf{A})$ soluble sugars (Fru = fructose, $\mathrm{Glu}=$ glucose, $\mathrm{Suc}=$ sucrose $),(\mathbf{B})$ organic acids $(\mathrm{Oxa}=$ oxalic acid, $\mathrm{Qui}=$ quinic acid, $\mathrm{Mal}=$ malic acid, Shi $=$ shikimic acid, $\mathrm{Cit}=$ citric acid $)$, and $(\mathbf{C})$ vitamin $\mathrm{C}(\mathrm{Vc})$.
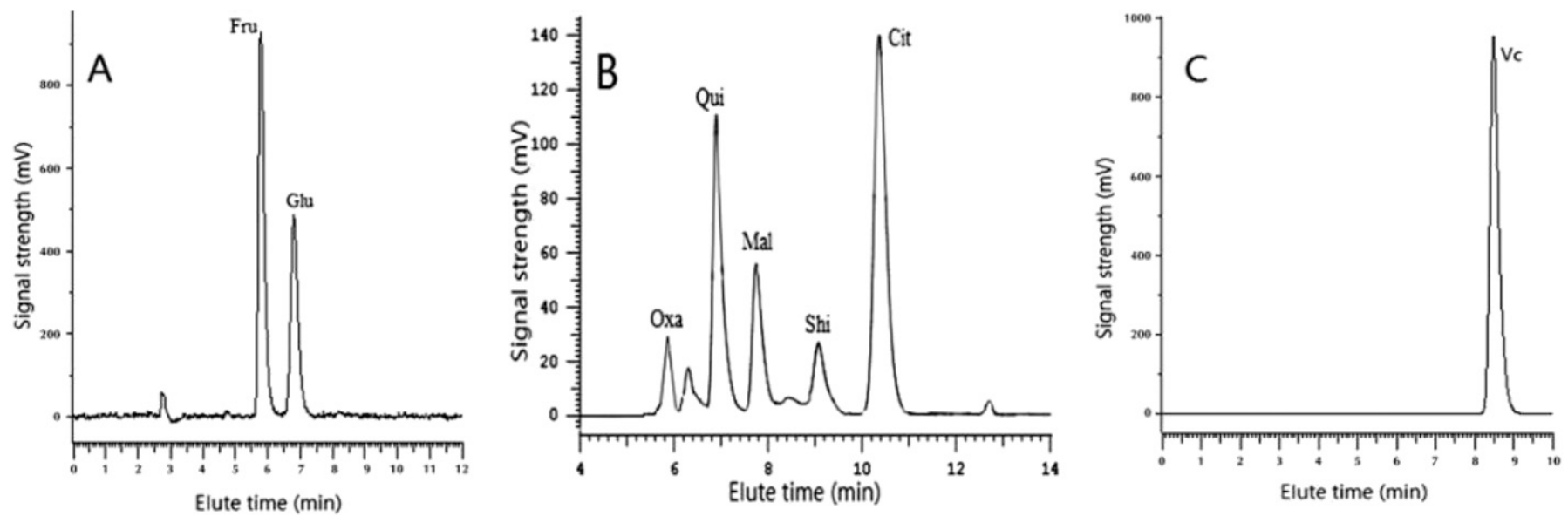

Fig. 2. High-performance liquid chromatogram of sugar and organic acids in Vaccinium uliginosum: $(\mathbf{A})$ soluble sugars $($ Fru $=$ fructose, Glu $=$ glucose, Suc $=$ sucrose $),(\mathbf{B})$ organic acids $(\mathrm{Oxa}=$ oxalic acid, Qui = quinic acid, Mal = malic acid, Shi = shikimic acid, Cit = citric acid $)$, and $(\mathbf{C})$ vitamin $\mathrm{C}(\mathrm{Vc})$. 
SugAR AND ACID COMPOSITIONS ACROSS POPUlations. Fructose $\left(18.60-38.54 \mathrm{mg} \cdot \mathrm{g}^{-1}\right)$ and glucose (15.77-35.08 $\left.\mathrm{mg} \cdot \mathrm{g}^{-1}\right)$ were the main sugars in fruit from the sampled populations of $V$. uliginosum as shown in Table 2. Fructose and glucose contents were similar (based on average values) across populations. Contrary to the report of Hirvi and Honkanen (1983), no sucrose was detected perhaps because sucrose levels decrease during ripening and are replaced by increased fructose and glucose levels (Šne et al., 2011). DFHI showed high $(P \leq 0.05)$ mean fructose $\left(38.54 \mathrm{mg} \cdot \mathrm{g}^{-1}\right)$, glucose $\left(35.08 \mathrm{mg} \cdot \mathrm{g}^{-1}\right)$, and total sugar $\left(73.62 \mathrm{mg} \cdot \mathrm{g}^{-1}\right)$ contents, followed by DFHII and MJ. Of these, one site is located in MJ and the other two in DFH, which are at the highest altitudes among the sampled sites. In fact, mean sugar contents of fruit from populations at these high-altitude sites were significantly higher $(P \leq 0.05)$ than sugar contents of fruit from populations at other low-altitude sites, including LJ.

Quinic (16.06-20.97 mg. $\left.\mathrm{g}^{-1}\right)$, citric (10.39-14.96 $\left.\mathrm{mg} \cdot \mathrm{g}^{-1}\right)$, and malic (4.28-7.47 $\mathrm{mg} \cdot \mathrm{g}^{-1}$ ) acids were the main organic acids in $V$. uliginosum fruit as shown in Table 2. Oxalic and shikimic acid contents were the lowest, which is consistent with the findings of Wei et al. (2014). Citric acid contents varied widely, showing a right skewed distribution. Mean vitamin $\mathrm{C}$ content was $0.26 \pm 0.03 \mathrm{mg} \cdot \mathrm{g}^{-1}$, which is similar to that reported previously (Fediuk et al., 2002). Mean quinic and citric acid contents of fruit from MJ were high $(P \leq 0.05)$ than those of fruit from the other sampled populations. However, vitamin $\mathrm{C}$ and oxalic acid contents of fruit from populations in MJ and DFH (high altitude) were significantly higher $(P \leq$ 0.05 ) than those in bilberries from populations at LJ (low altitude). Interestingly, the mean total acid content little differed across the 10 sampled populations.

Sugar-to-acid ratio and total sugar content are important factors determining the sweetness and quality of berries (Mikulic et al., 2015). Mean sugar-to-acid ratio of $V$. uliginosum in our populations was 0.99 to 2.09. The highest sugar-to-acid ratio was detected in bilberries from DFHI, whereas the lowest was detected in fruit from LJVII. One sample from MJ-7 showed the highest sugar-to-acid ratio among all tested samples, followed by two samples from DFHII-1 and DFHII-8.

SUgar AND ACID COMPOSITIONS WITHIN POPULATIONS. Variations in sugar and acid contents within the 10 sampled populations are presented in Fig. 3. Wide variation in sugar content within populations was observed in this study. The highest fructose, glucose, and total sugar contents were detected in a samples from MJ-7 as shown in Fig. 3A-C. The variation in sugar content within population was minimal in DFHI. The variation in fructose content within LJIV population was between 16.24 and $26.11 \mathrm{mg} \cdot \mathrm{g}^{-1}$ (except for LJIV-8 sample); variation in glucose content within LJIII population was between 11.99 and $24.98 \mathrm{mg} \cdot \mathrm{g}^{-1}$ (except LJIII-5 sample).

Quinic acid content of fruit from DFHII and LJIII were more variable than quinic acid content of fruit from other populations (Fig. 3D), but quinic acid content was the highest in fruit from MJ, with sample MJ-2 showing the highest content within population. Citric acid contents of samples LJII-6 and LJII-8 were higher than those of other samples from the population (Fig. 3E). Citric acid content of sample MJ-7 was the lowest among all samples (8.67

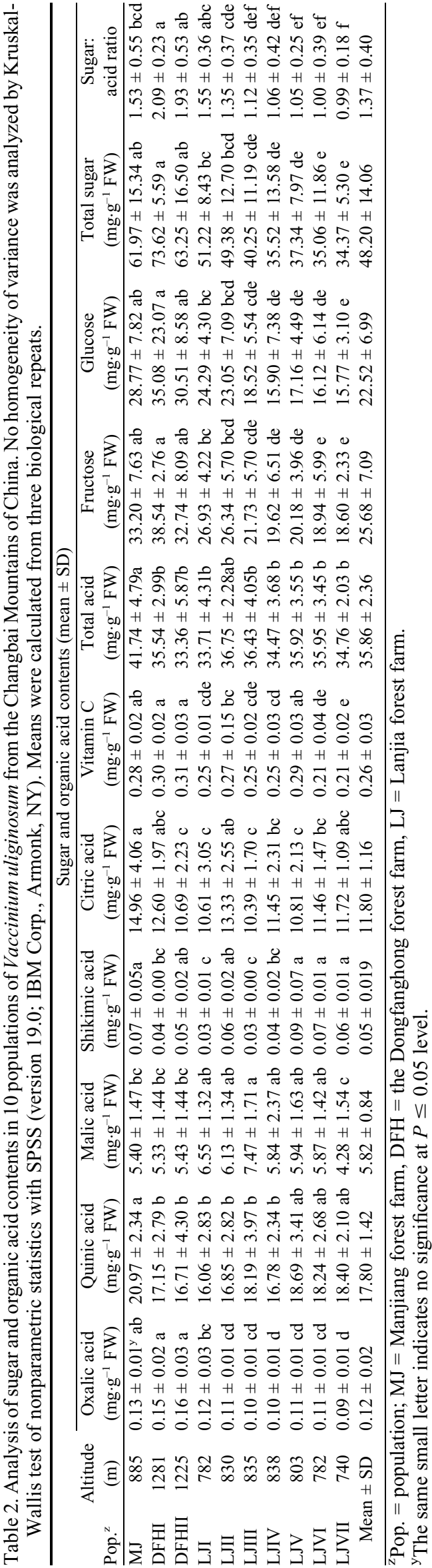

J. Amer. Soc. Hort. ScI. 144(6):420-428. 2019. 

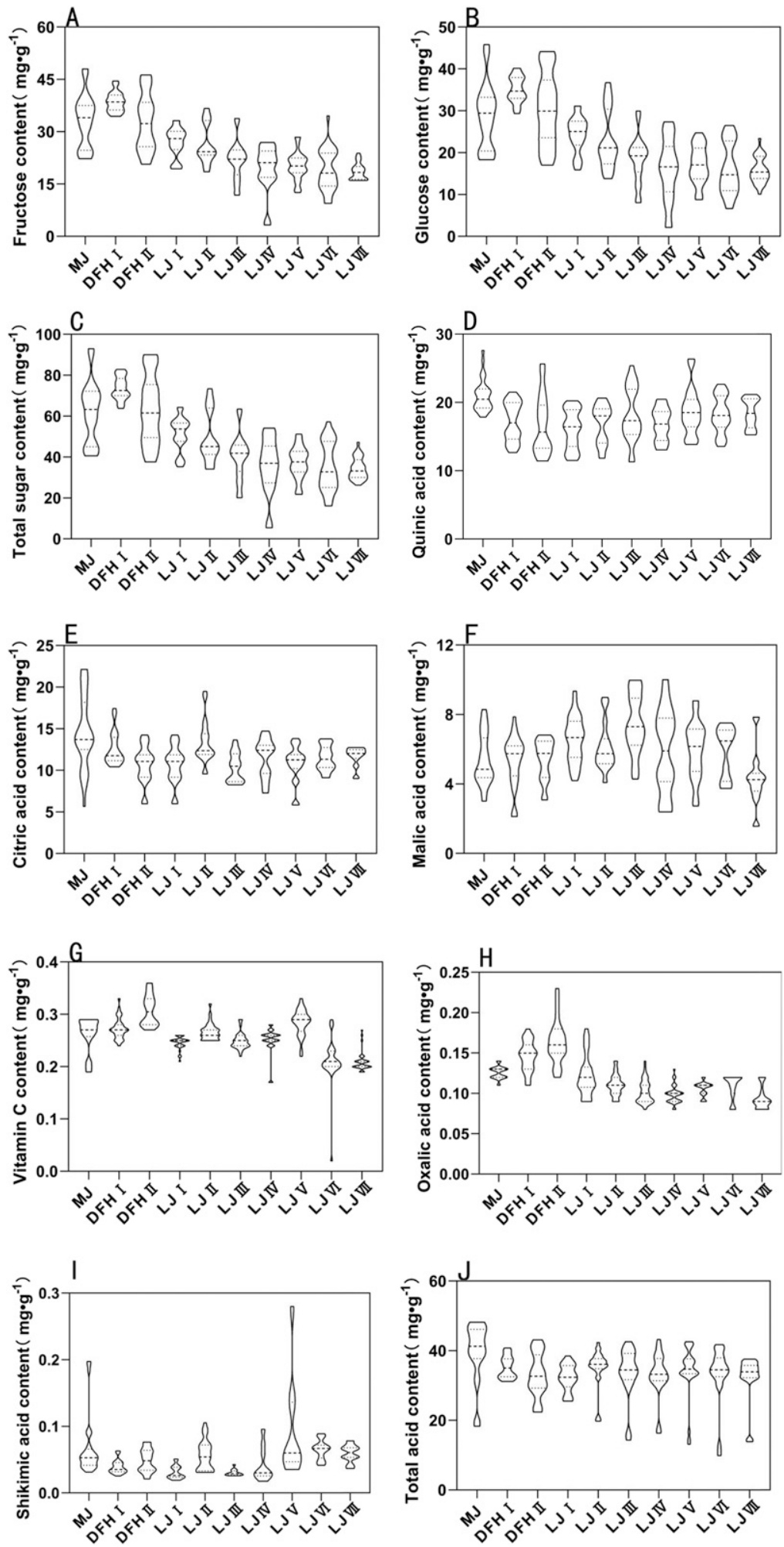

Fig. 3. Range and distribution of sugar, organic acid content in populations of Vaccinium uliginosum from the Changbai Mountains of China (MJ = Manjiang forest farm, DFH = Dongfanghong forest farm, LJ = Lanjia forest farm). We drew violin chart using OriginPro (version 2018; OriginLab, Northampton, MA). The horizontal lines in the interior of the violin chart are the median values. The height in a violin chart is equal to the interquartile distance.

$\left.\mathrm{mg} \cdot \mathrm{g}^{-1}\right)$. The highest malic acid content was $7.86 \mathrm{mg} \cdot \mathrm{g}^{-1}$ in LJVII-8, whereas LJVII-5 contained only $1.56 \mathrm{mg} \cdot \mathrm{g}^{-1}$ (Fig. 3F). Vitamin C content was very low $\left(0.02 \mathrm{mg} \cdot \mathrm{g}^{-1}\right)$ in LJIV-9 (Fig.
3G). The highest oxalic acid content was detected in DFHII-1, whereas oxalic acid contents in other populations ranged from 0.11 to $0.19 \mathrm{mg} \cdot \mathrm{g}^{-1}$ (Fig. 3H). The highest shikimic acid content was detected in LJV (Fig. 3I). The highest total acid content was detected in MJ-9 and the lowest in DFHII-9 (Fig. 3J).

Correlation between SUgar and ORGANIC ACID CONTENTS. The correlation matrix of sugar and organic acid contents of $V$. uliginosum is shown in Table 3. Oxalic acid content was significantly and positively correlated with vitamin $\mathrm{C}$ content $(\mathrm{r}=0.41)$. Quinic acid content was significantly and positively correlated with shikimic $(\mathrm{r}=$ $0.16)$ and citric acid contents $(\mathrm{r}=0.23)$. Quinic $(\mathrm{r}=0.81)$ and citric acid contents were significantly and positively correlated with total acid content $(r=0.64)$. Fructose and glucose contents were significantly and positively correlated $(r=0.97)$, probably because the two sugars can easily replace each other during metabolism (Buchanan et al., 2000; Taiz and Zeiger, 2006). Total sugar content was significantly and positively correlated with fructose $(r=0.99)$ and glucose $(r=0.99)$ content, whereas total sugar was positively correlated with oxalic $(\mathrm{r}=$ $0.57)$, citric $(\mathrm{r}=0.16)$, and vitamin $\mathrm{C}$ content $(\mathrm{r}=0.25)$. Glucose was significantly and negatively correlated with quinic $(\mathrm{r}=$ $-0.14)$, citric, and malic acid contents $(\mathrm{r}=$ -0.34 ). Total acid content was not correlated with fructose content.

Principal component analysis. We used PCA to analyze the multivariate relationship between sugar and organic acid contents in $100 \mathrm{~V}$. uliginosum fruit collected from 10 populations. The eigenvalues for the first four PCs were all greater than 1.0 (Fig. 4). Principal components 1 through 4 (PC1-4) explained a high percentage of the total variance $(35.6 \%$ for $\mathrm{PC} 1,22.9 \%$ for PC2, $14.4 \%$ for PC $3,10.7 \%$ for PC4). The cumulative contribution of the first four $\mathrm{PC}$ axes (PC1-PC4) was $83.6 \%$, indicating that the ordination axes explained $83.6 \%$ of variation inherent to the input data. Quinic, malic, shikimic, and total acid contents were slightly and negatively correlated with PC1, whereas the other sugar and acid contents were positively correlated with PC1 (Fig. 5). Oxalic acid, malic acid, and glucose were positively correlated with PC2. The correlations among PC2, PC3, and sugar-to-acid ratio showed a similar trend, that is, certain sugar and organic acid contents, such as glucose and malic acid, were the main components of PC 3 and PC2. The PC3 and PC4 axes mainly show that fructose, glucose, and total sugar positively correlate with axes PC3 and PC4. 
Table 3. Analysis of correlation between soluble sugar and organic acids in Vaccinium uliginosum. We verified any linear relationship between parameters with SPSS (version 19.0; IBM Corp., Armonk, NY) and determined degree of correlation with Pearson correlation coefficients. Total sugar content was significantly and positively correlated with fructose and glucose contents. Total acid content was not correlated with fructose content.

\begin{tabular}{|c|c|c|c|c|c|c|c|c|c|c|}
\hline & Oxalic acid & Quinic acid & Malic acid & Shikimic acid & Citric acid & Vitamin C & Fructose & Glucose & Total acid & Total sugar \\
\hline Oxalic acid & 1 & & & & & & & & & \\
\hline Malic acid & $-0.13 *$ & $-0.20 * *$ & 1 & & & & & & & \\
\hline Citric acid & 0.05 & $0.23 * *$ & $-0.34 * *$ & $0.17 * *$ & 1 & & & & & \\
\hline Vitamin C & $0.41 * *$ & 0.02 & -0.01 & $0.12 *$ & 0.01 & 1 & & & & \\
\hline Fructose & $0.56^{* *}$ & -0.10 & -0.11 & -0.09 & $0.19 * *$ & $0.25 * *$ & 1 & & & \\
\hline Total sugar & $0.57 * *$ & $-0.12 *$ & -0.09 & -0.01 & $0.16^{* *}$ & $0.25 * *$ & $0.99 * *$ & $0.99 * *$ & -0.03 & 1 \\
\hline
\end{tabular}

Ns, $* * *$ Nonsignificant or significant at $P \leq 0.05$ or 0.01 , respectively.

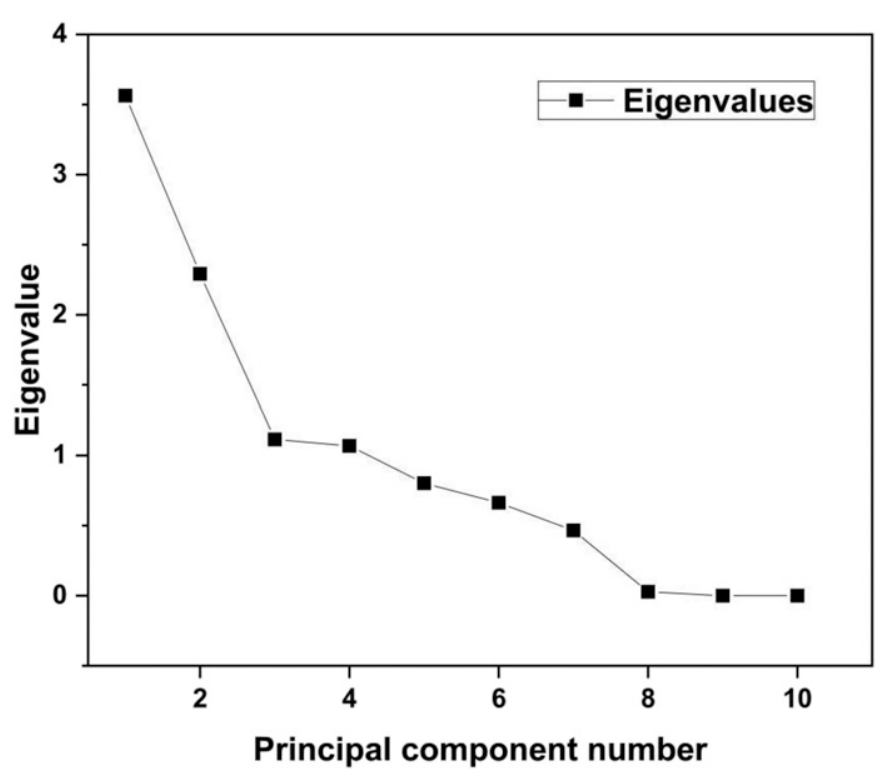

Fig. 4. A scree plot of the percent variability in Vaccinium uliginosum explained by each principal component. The eigenvalues of the first four principal components are greater than 1 , and the cumulative contribution rate is more than $80 \%$. Therefore, the first four principal components are mainly analyzed.

We also plotted PCA scores of sugar and acid contents of the 100 samples (Fig. 6). The closer the samples were on the plot, the more similar were their compositions. The first four principal components effectively separated populations, especially on the PC1 and PC2 axes. Most samples from MJ, DFHI, and DFHII were grown at high altitude and low latitudes, all distributed on the positive side of the PC1 axis. The average altitude of these three populations was $1130 \mathrm{~m}$, and the latitude was $43^{\circ} 43^{\prime} \mathrm{N}$. Their fructose and glucose contents were higher than the other populations. Samples from LJI and LJII populations at low altitude and high latitude were mostly distributed toward the middle of the PCA diagram (at the intersection of the PC1 and PC2 coordinate axes). The average altitude of the two populations is $806 \mathrm{~m}$ and the latitude is $43^{\circ} 04^{\prime} \mathrm{N}$ where malic acid content is high. LJIII, LJIV, LJV, LJVI, and LJVII are located at relatively low altitude and high latitudes; samples from these populations were mostly distributed on the negative side of the PC1 axis. The average elevation of the five LJ populations was $799 \mathrm{~m}$ and the latitude $41^{\circ} 04^{\prime} \mathrm{N}$. In addition, their quinic acid content was high. Ordination results showed that $\mathrm{PC} 1 / \mathrm{PC} 2$ and $\mathrm{PC} 3 / \mathrm{PC} 4$ diagrams effectively represent the distribution of sugar and acid components in different populations.

Correlation of SUgar AND ORganic ACID CONTENTS WiTH SPATIAL DisTRIBUTION. Spatial distribution of plants influences plant metabolism. Anthocyanins and flavonoids of $V$. uliginosum are reportedly related to spatial distribution (Lätti et al., 2010; Wang et al., 2014).

In our study, when we explored the relationships among fruit sugars, organic acids, and spatial distributions (altitude and latitude) of $V$. uliginosum fruit, we found that the contents of fructose, glucose, total sugars, and oxalic acid and sugar-to-acid ratios were higher in plants growing above $800 \mathrm{~m}$ because all these factors were positively correlated with altitude (Fig. 7A, $\mathrm{C}, \mathrm{E}$, and F). We found that the vitamin $\mathrm{C}$ content of fruit was also higher at higher elevations as shown in Fig. 7A, However, we found that the contents of shikimic, malic acid, and quinic acid were not related to altitude (Fig. 7A and B). This may be due to genetic differences between populations at different altitudes. Total acid content was lower at lower elevations (Fig. 7D), but the degree of fit of the regression was low; thus, there was no significant relationship with altitude. Fructose, glucose, and total sugar contents were negatively correlated with latitude, but there was no significant correlation between contents of various organic acids and latitude. Similarly, previous studies have speculated that sea buckthorns growing at low latitudes show high total sugar content and sugar-to-acid ratio (Tang et al., 2001; Tiitinen et al., 2005). Zheng et al. (2010) found that there was no significant difference between citric acid and quinic acid content of gooseberry at different latitudes. Contents of sugars and organic acids were the same in fruit from LJI and LJVI located at the same altitude, but these contents differed from LJI and LJII fruit growing at the same latitude. This difference may be due to a combination of differing growth environments (e.g., soils and microclimates), genetics, or other environmental factors (Akerstrom et al., 2010; Sønsteby et al., 2015; Uleberg et al., 2012).

\section{Conclusion}

There were significant differences in sugar and organic acid contents of various $V$. uliginosum populations in the 

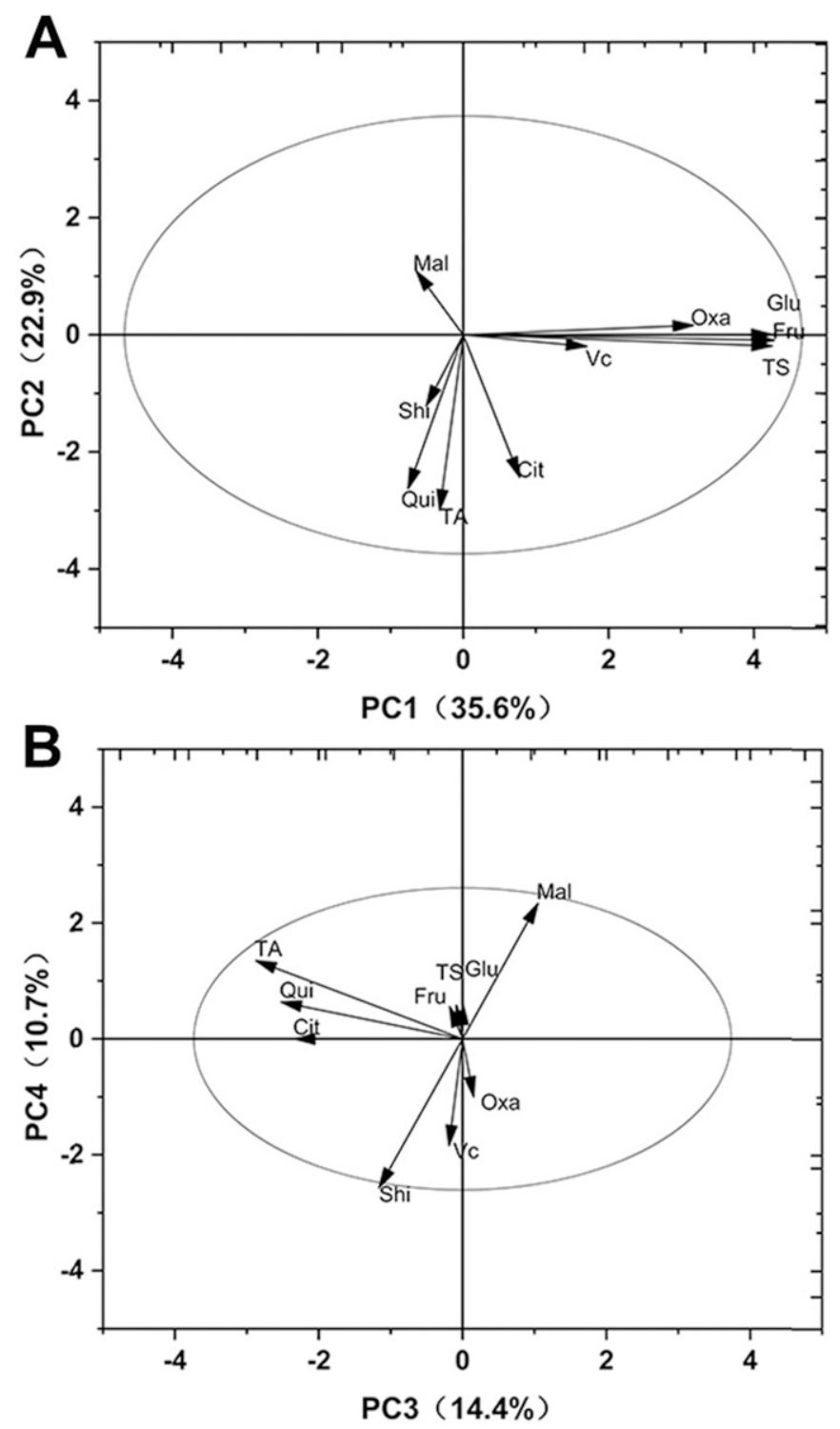

Fig. 5. Plots of sugars and organic acids in Vaccinium uliginosum for the first four principal components in 10 different populations from the Changbai Mountains of China. The circle is 1-radius. Original data on sugars and acid is expressed as milligrams per gram; $\mathrm{Mal}=$ malic acid; $\mathrm{Shi}=$ shikimic acid; Qui $=$ quinic acid; $\mathrm{Cit}=$ citric acid; Oxa $=$ oxalic acid; $\mathrm{TA}=$ total acid; Fru $=$ fructose; Glu = glucose; TS = total sugar.

Changbai Mountains. Quinic, citric, and malic acids were the most abundant organic acids in $V$. uliginosum fruit, which accounted for $49.65 \%, 32.90 \%$, and $16.24 \%$ of total acid contents, respectively. Fructose and glucose were the main soluble sugars, and their contents ranged from 18.60 to $38.54 \mathrm{mg} \cdot \mathrm{g}^{-1}$ and 15.77 to $35.08 \mathrm{mg} \cdot \mathrm{g}^{-1}$, respectively. DFHI was an excellent population with high sugar and low acid content to explore for breeding purposes. In sample MJ-7, the total sugar content was $92.40 \mathrm{mg} \cdot \mathrm{g}^{-1}$, total acid content was $31.71 \mathrm{mg} \cdot \mathrm{g}^{-1}$, and sugar-to-acid ratio was 2.92 , which were much higher than the rest of samples, making this sample potentially important germplasm for breeding.

Sugar and organic acid contents of fruit were related to altitude and latitude of the populations from which they were
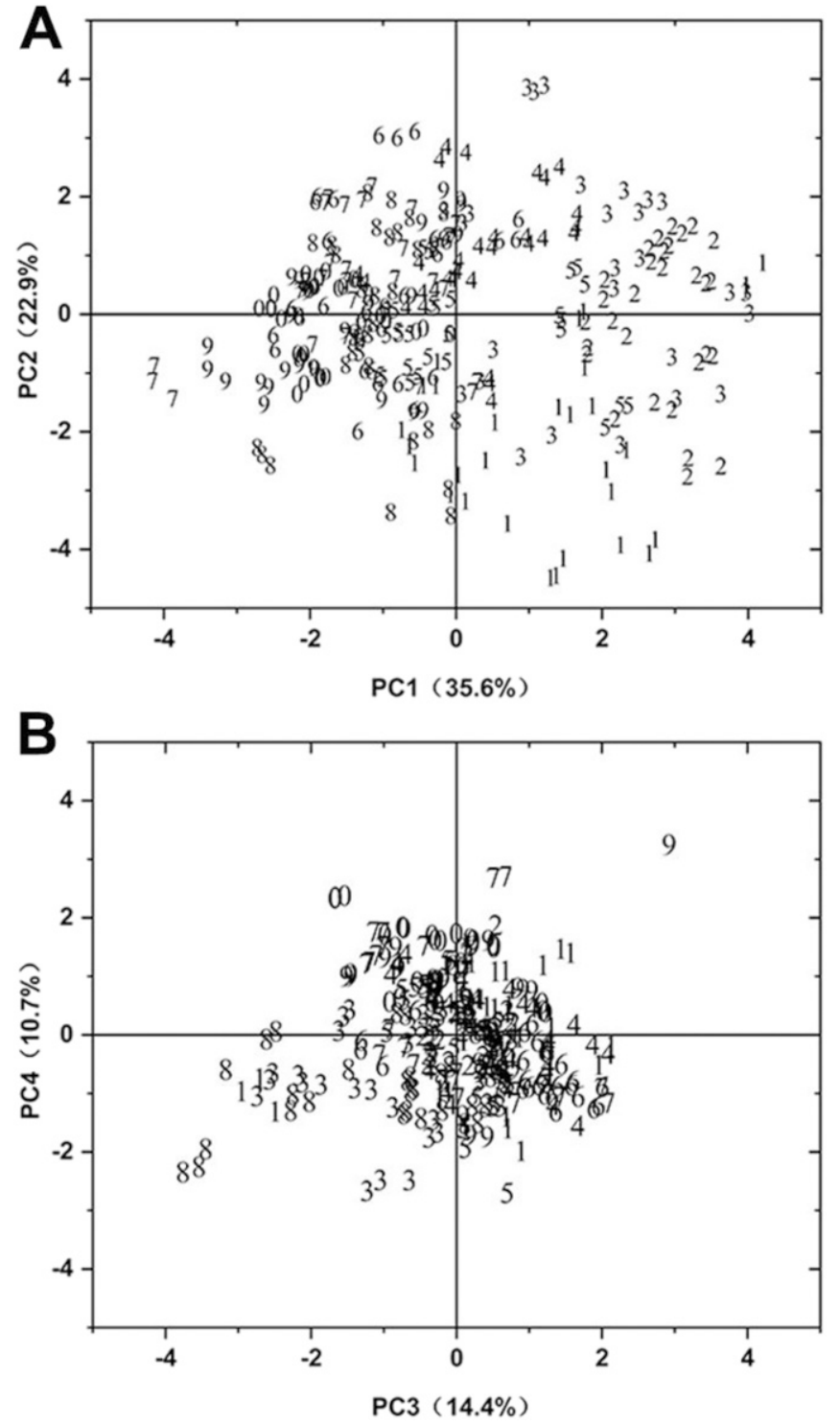

Fig. 6. Positions of principal component scores of 100 Vaccinium uliginosum samples from the Changbai Mountains of China (indicated in numbers): according PC1-PC2 (A) and PC3-PC4 (B). Number representation: 1) MJ, 2) DFHI, 3) DFHII, 4) LJI, 5) LJII, 6) LJIII, 7) LJIV, 8) LJV, 9) LJVI, and 0) LJVII $(\mathrm{MJ}=$ Manjiang forest farm, $\mathrm{DFH}=$ Dongfanghong forest farm, $\mathrm{LJ}=$ Lanjia forest farm).

harvested. Fructose, glucose, and total sugars content were positively correlated with altitude and negatively correlated with latitude. Oxalic acid content and sugar-to-acid ratio were positively correlated with altitude. However, there was no significant correlation between organic acid and latitude. To a certain extent, these relationships reflect the ecological characteristics and metabolic composition of the various populations in the Changbai Mountains and their spatial distributions, further demonstrating that altitude and latitude are important factors affecting sugar and organic acid contents in $V$. uliginosum fruit. Variation in sugar and acid contents and compositions of fruit from populations growing at the same altitude or latitude may be a response to the interaction of plants with their environment, their genome, or other environmental factors. 

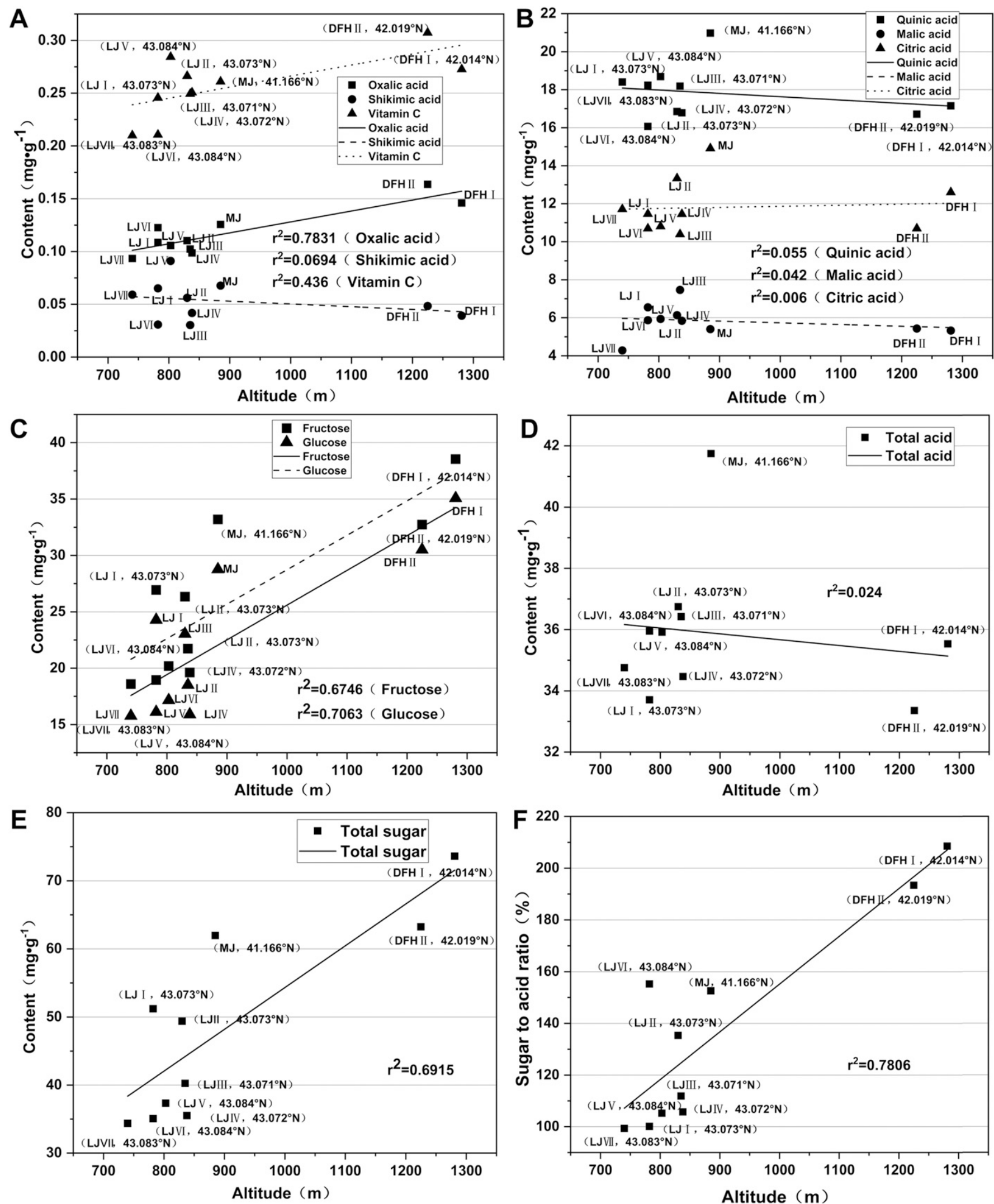

Fig. 7. Correlation between sugar and organic acids in Vaccinium uliginosum populations from the Changbai Mountains of China and spatial distribution. Population, altitude, and latitude are indicated in parentheses on the plot $(\mathrm{MJ}=$ Manjiang forest farm, $\mathrm{DFH}=\mathrm{Dongfanghong}$ forest farm, $\mathrm{LJ}=\mathrm{Lanjia}$ forest farm $)$. 


\section{Literature Cited}

Akerstrom, A., L. Jaakola, U. Bang, and A. Jaderlund. 2010. Effects of latitude-related factors and geographical origin on anthocyanidin concentrations in fruits of Vaccinium myrtillus L. (bilberries). J. Agr. Food Chem. 58:11939-11945.

Barett, D.M., L. Somogyi, and H. Ramaswamy. 2005. Processing fruits: Science and technology. 2nd ed. CRC Press, New York, NY. Buchanan, B.B., W. Gruissem, and R.L. Jones. 2000. Biochemistry and molecular biology of plant. Amer. Soc. Plant Physiologists, Rockville, MD.

Fediuk, K., N. Hidiroglou, M. René, and H.V. Kuhnlein. 2002. Vitamin $\mathrm{C}$ in Inuit traditional food and women's diets. J. Food Compos. Anal. 15:221-235.

Graae, B.J., I.G. Alsos, and R. Ejrnaes. 2008. The impact of temperature regimes on development, dormancy breaking and germination of dwarf shrub seeds from arctic, alpine and boreal sites. Plant Ecol. 198:275-284.

Hirvi, T. and E. Honkanen. 1983. The aroma of some hybrids between high-bush blueberry (Vaccinium corymbosum L.) and bog blueberry (Vaccinium uliginosum L.). Z. Lebensm. Unters. Forsch. 176:346349.

Jacquemart, A.L. 1996. Vaccinium uliginosum L. J. Ecol. 84:771-785. Kafkas, E., M. Kosar, N. Türemis, and K. Baser. 2006. Analysis of sugars, organic acids and vitamin c contents of blackberry genotypes from Turkey. Food Chem. 97:732-736.

Kalt, W., C.F. Forney, A. Martin, and R.L. Prior. 1999. Antioxidant capacity, vitamin $\mathrm{C}$, phenolics, and anthocyanins after fresh storage of small fruits. J. Agr. Food Chem. 47:4638-4644.

Kim, Y.H., C.Y. Bang, E.W. Won, J.P. Kim, and S.Y. Choung. 2009. Antioxidant activities of Vaccinium uliginosum L. extract and its active components. J. Med. Food 12:885-892.

Kraujalytė, V., P.R. Venskutonis, A. Pukalskas, L. Česonienè, and R. Daubaras. 2015. Antioxidant properties, phenolic composition and potentiometric sensor array evaluation of commercial and new blueberry (Vaccinium corymbosum) and bog blueberry (Vaccinium uliginosum) genotypes. Food Chem. 188:583-590.

Lätti, A.K., L. Jaakola, K.R. Riihinen, and P.S. Kainulainen. 2010. Anthocyanin and flavonol variation in bog bilberries (Vaccinium uliginosum L.) in Finland. J. Agr. Food Chem. 58:427-433.

Lätti, A.K., K.R. Riihinen, and P.S. Kainulainen. 2008. Analysis of anthocyanin variation in wild populations of bilberry (Vaccinium myrtillus L.) in Finland. J. Agr. Food Chem. 56:190-196.

Liu, H.F., B.H. Wu, P.G. Fan, S.H. Li, and L.S. Li. 2006. Sugar and acid concentrations in 98 grape cultivars analyzed by principal component analysis. J. Sci. Food Agr. 86:1526-1536.

Liu, J., W. Zhang, H. Jing, and D.G. Popovich. 2010. Bog bilberry (Vaccinium uliginosum L.) extract reduces cultured HepG2, Caco-2, and 3T3-L1 cell viability, affects cell cycle progression, and has variable effects on membrane permeability. J. Food Sci. 75:103-107. Makus, D.J. and J.R. Morris. 1987. Highbush vs. rabbiteye blueberry: A comparison of fruit quality. Arkansas Farm Res. Arkansas Agr. Expt. Sta. 36:5.

Mikulic, P.M., V. Schmitzer, A. Slatnar, F. Stampar, and R. Veberic. 2015. A comparison of fruit quality parameters of wild bilberry (Vaccinium myrtillus L.) growing at different locations. J. Sci. Food Agr. 95:776-785.

Poll, L. 1981. Evaluation of 18 apple varieties for their suitability for juice production. J. Sci. Food Agr. 32:1081-1090.
Ryan, J.J. and J.A. Dupont. 1973. Identification and analysis of the major acids from fruit juices and wines. J. Agr. Food Chem. 21:45-49.

Saftner, R., J. Polashock, M. Ehlenfeldt, and B. Vinyard. 2008. Instrumental and sensory quality characteristics of blueberry fruit from twelve cultivars. Postharvest Biol. Technol. 49:19-26.

Šne, E, S. Kampuse, and B. Elga. 2011. The composition of sugars and sugar-acid ratio of highbush blueberry varieties grown in Latvia. Res. Rural Dev, 1:140-144.

Sønsteby, A., N. Opstad, and O.M. Heide. 2015. Effects of summer temperature on growth and flowering in six black currant cultivars (Ribes nigrum L.). J. Pomol. Hort. Sci. 87:157-164.

Su, S., L.J. Wang, J. Wu, B. Li, W.W. Wang, and L. Wang. 2016. Review: Chemical compositions and functions of Vaccinium uliginosum. Chinese Bul. Bot. 51:691-704.

Taiz, L. and E. Zeiger. 2006. Plant physiology. 4th ed. Sinauer Assoc., Sunderland, MA.

Tang, X., L. Kä, N. Inen, and H. Tuorila. 2001. Sensory and hedonic characteristics of juice of sea buckthorn (Hippophae rhamnoides L.) origins and hybrids. LWT Food Sci. Technol 34:102-110.

Tiitinen, K.M., M.A. Hakala, and H.P. Kallio. 2005. Quality components of sea buckthorn (Hippophaë rhamnoides) varieties. J. Agr. Food Chem. 53:1692-1699.

Uleberg, E., J. Rohloff, L. Jaakola, K. Trost, O. Junttila, and H. Häggman. 2012. Effects of temperature and photoperiod on yield and chemical composition of northern and southern clones of bilberry (Vaccinium myrtillus L.). J. Agr. Food Chem. 60:10406-10414.

Wang, E.L., Y.G. Yin, C.N. Xu, and J.B. Liu. 2014. Isolation of highpurity anthocyanin mixtures and monomers from blueberries using combined chromatographic techniques. J. Chromatography 1327:39-48.

Wang, S.Y., C.T. Chen, and C.Y. Wang. 2009. The influence of light and maturity on fruit quality and flavonoid content of red raspberries. Food Chem. 112:676-684.

Wei, M., P. Gu, C.J. Li, H.Y. Yang, and S.X. Liu. 2014. Determination of 7 organic acids in Vaccinium uliginosum products by HPLC. China Brewing 33:145-148.

Wu, B.H., B. Quilot, J. Kervella, M. Génard, and S.H. Li. 2003. Analysis of genotypic variation of sugar and acid contents in peaches and nectarines through the principle component analysis. Euphytica 132:375-384.

Wu, Z.Y., P.H. Raven, and D.Y. Hong. 2005. Flora of China. Science Press, Beijing, China.

Yang, Y., B.H. Cui, Z.W. Tan, B.X. Song, H.N. Cao, and C.W. Zong. 2018. RNA sequencing and anthocyanin synthesis-related genes expression analyses in white-fruited Vaccinium uliginosum. BMC Genomics 19:930.

Yin, L., Y.L. Pi, and M.N. Zhang. 2012. The effect of Vaccinium uliginosum on rabbit retinal structure and light-induced function damage. Chin. J. Integr. Med. 18:299-303.

Zheng, J., K. Heikki, and Y. Baoru. 2010. Effects of latitude and weather conditions on sugars, fruit acids and ascorbic acid in currant (Ribes sp.) cultivars. J. Sci. Food Agr. 89:2011-2023.

Zheng, J., H. Kallio, K. Linderborg, and B. Yang. 2011. Sugars, sugar alcohols, fruit acids, and ascorbic acid in wild chinese sea buckthorn (Hippopha rhamnoides ssp. sinensis) with special reference to influence of latitude and altitude. Food Res. Int. 44:2018-2026.

Zong, C.L., M. Deng, C.W. Zong, H.N. Cao, and W.J. Li. 2011. Research progress on Vaccinium uliginosum Linn. Chinese J. Northern Hort. 12:173-176. 